\title{
Synergistic heterozygosity for TGF $\beta 1$ SNPs and BMPR2 mutations modulates the age at diagnosis and penetrance of familial pulmonary arterial hypertension
}

John A. Phillips III, MD, ${ }^{1}$ Justin S. Poling, BS, ${ }^{1}$ Charles A. Phillips, BS, MS ${ }^{1}$ Krista C. Stanton, BS, ${ }^{1}$ Eric D. Austin, MD, ${ }^{2}$ Joy D. Cogan, PhD, ${ }_{1}^{1}$ Lisa Wheeler, BS, ${ }^{2}$ Chang Yu, PhD, ${ }^{3}$ John H. Newman, MD, ${ }^{2}$ Harry C. Dietz, MD, ${ }^{4}$ and James E. Loyd, $M D^{2}$

\begin{abstract}
Purpose: We hypothesized that functional TGF $\beta 1$ SNPs increase TGF $\beta$ /BMP signaling imbalance in $B M P R 2$ mutation heterozygotes to accelerate the age at diagnosis, increase the penetrance and SMAD2 expression in familial pulmonary arterial hypertension. Methods: Single nucleotide polymorphism genotypes of BMPR2 mutation heterozygotes, age at diagnosis, and penetrance of familial pulmonary arterial hypertension were compared and SMAD2 expression was studied in lung sections. Results: BMPR2 mutation heterozygotes with least active -509 or codon 10 TGFB1 SNPs had later mean age at diagnosis of familial pulmonary arterial hypertension (39.5 and 43.2 years) than those with more active genotypes (31.6 and 33.1 years, $P=0.03$ and 0.02 , respectively). Kaplan-Meier analysis also showed that those with the less active single nucleotide polymorphisms had later age at diagnosis. BMPR2 mutation heterozygotes with nonsense-mediated decay resistant BMPR2 mutations and the least, intermediate and most active -509 TGF 31 SNP genotypes had penetrances of 33,72 , and $80 \%$, respectively $(P=0.003)$, whereas those with $0-1,2$, or 3-4 active single nucleotide polymorphism alleles had penetrances of 33,72 , and $75 \%(P=0.005)$. The relative expression of TGF $\beta 1$ dependent SMAD2 was increased in lung sections of those with familial pulmonary arterial hypertension compared with controls. Conclusions: The TGF 11 SNPs studied modulate age at diagnosis and penetrance of familial pulmonary arterial hypertension in BMPR2 mutation heterozygotes, likely by affecting TGF $\beta / B M P$ signaling imbalance. This modulation is an example of Synergistic Heterozygosity. Genet Med 2008:10(5):359-365.
\end{abstract}

Key Words: synergistic heterozygosity, TGF $\beta 1$ SNPs, BMPR2 mutations, FPAH

Pulmonary arterial hypertension $(\mathrm{PAH})$ is a progressive, fatal disease caused by proliferative occlusion of the pulmonary arteries due to vascular remodeling. Familial PAH (FPAH) is an autosomal dominant disorder that exhibits variable expression, reduced penetrance, skewed female:male ratio of 2.4:1 and anticipation. ${ }^{1,2}$ In 2000, mutations in the Bone Morphogenetic Protein Receptor Type 2 (BMPR2) gene in the TGF $\beta$ Superfamily were reported to cause FPAH. ${ }^{3,4}$ Subsequently, over 140 different BMPR2 mutations have been detected in

\footnotetext{
From the Divisions of ${ }^{1}$ Medical Genetics and ${ }^{2}$ Pulmonary Medicine, and ${ }^{3}$ Department of Biostatistics, Vanderbilt University School of Medicine, Nashville, Tennessee; and ${ }^{4}$ McKusick-Nathans Institute of Genetic Medicine, Johns Hopkins University School of Medicine, Baltimore, Maryland.

John A. Phillips III, MD, DD 2205 Medical Center North, Vanderbilt University School of Medicine, Nashville,TN 27232-2578.E-mail: john.a.phillips@vanderbilt.edu.

Disclosure: The authors declare no conflict of interest.

Submitted for publication November 30, 2007.

Accepted for publication February 25, 2008.

DOI: 10.1097/GIM.0b013e318172dcdf
}

FPAH and most are predicted to cause a loss of receptor function (haploinsufficiency), either through missense, nonsense or frameshift mutations, or through splicing errors. ${ }^{5-8}$ Recently, these as well as deletion/duplication BMPR2 mutations were reported to occur in the majority (82\%) of FPAH cases. ${ }^{9}$

Although BMPR2 mutations cause FPAH, the pathophysiology of this complex disease remains unclear. ${ }^{10}$ The observation that many of those with a BMPR2 mutation do not develop FPAH suggests that susceptibility and modifier genes, anticipation, as well as environment may all play important roles in determining the reduced penetrance, skewed gender ratio, variations in clinical severity and progression, and possibly differences seen in the response to treatment.

Anticipation is the tendency in certain genetic disorders for those in successive generations to present at an earlier age and/or with more severe manifestations. It is often seen in disorders resulting from the expression of a trinucleotide repeat expansion that tends to increase in size and have a more significant effect when passed from one generation to the next. ${ }^{11}$ No trinucleotide repeat or other expansions in BMPR2 
have been reported to cause FPAH and the molecular basis of anticipation in FPAH is poorly understood. ${ }^{1,2}$

Nonsense-mediated decay (NMD) is a messenger RNA (mRNA) surveillance system that degrades transcripts containing premature termination codons (PTCs) to prevent translation of unnecessary or harmful transcripts. We have previously shown by analysis of BMPR2 mRNAs that some mutations produce stable transcripts whereas others generate PTCs which trigger mRNA degradation by NMD. ${ }^{7,9}$ Failure to eliminate mRNAs with PTCs can result in synthesis of abnormal proteins that can be toxic to cells through dominant negative or gain of function effects. ${ }^{12,13}$

Ligands for BMPR2, called bone morphogenetic proteins (BMPs), are signaling molecules that are also members of the TGF $\beta$ superfamily. BMPs are synthesized and released from a variety of cell types including pulmonary artery smooth muscle and endothelial cells. They induce formation of heterodimeric complexes between Type I and II receptors that activate downstream signaling pathways through phosphorylation and/or mitogen activated kinases. ${ }^{14,15}$ SMADS1, 5, and 8 mediate intracellular signaling of BMP whereas SMADS2 and 3 transduce TGF $\beta$ signaling. SMAD4 is a common mediator that is required for both pathways. ${ }^{16}$ In addition, other signaling systems that influence vascular tone, function, and remodeling have been associated with PAH. ${ }^{17-19}$ Multiple studies show that serotonin and its transporter (SERT) play a critical role in the pulmonary vascular smooth muscle hyperplasia and vascular remodeling found in PAH and SERT polymorphisms weakly correlate with severity or age at diagnosis (AAD) of FPAH. ${ }^{20-22}$

Susceptibility genes have functional variants that affect causes of disease. Modifier genes differ in that they are genetic variants that affect the clinical manifestation of disease (as opposed to liability). In contrast to susceptibility genes, the identification of modifier genes has proven elusive. ${ }^{23}$ TGF $\beta$ single nucleotide polymorphisms (SNPs) have been reported to modify the severity of cystic fibrosis (CF). ${ }^{24}$ Drumm et al. ${ }^{24}$ reported significant allelic and genotypic associations between the CF phenotype and -509 and codon 10 TGF $\beta 1$ SNPs. The -509 TGF $\beta$ C/T SNP explains $8.2 \%$ of the additive genetic variance in TGF $\beta$ concentration due to effects on a Yin Yang 1 binding site and transcriptional suppression of the $-509 \mathrm{C}$ allele by AP1. ${ }^{25-27}$ The codon 10 C SNP allele with higher levels of TGF $\beta 1$ mRNA and protein exhibits association with pulmonary fibrotic and chronic obstructive pulmonary disease. ${ }^{28-30}$ The more active -509 TT and codon 10 CC TGF $\beta 1$ SNP genotypes associate in CF studies with worse lung function, and the TGF $\beta 1$ codon 10 CC genotype had an odds ratio of 2.2 with the most severe reductions in forced expiratory volume in the first second (FEV1). ${ }^{24}$ Although the codon 10 CC SNP genotype correlated with increased TGF $\beta$ expression, secretion and levels in a variety of other conditions, the mechanisms by which the SNP genotype may function with other genetic or environmental factors to affect the severity of CF is unknown. ${ }^{23}$

Variation in the severity of symptoms of inborn errors is often attributed to the effects of specific mutations. However, some affected individuals can have partial defects in more than one pathway, or at multiple steps in a single pathway. These individuals can show clinical symptoms consistent with a homozygous defect in the affected pathway even though they do not have a complete deficiency in any one enzyme. Vockley et al. ${ }^{31}$ and Schuler et al. ${ }^{32}$ coined the term "Synergistic Heterozygosity" for such individuals having clinically significant metabolic problems due to the compound effects of these partial defects. We have incorporated this idea of Synergistic Heterozygosity into our hypothesis that heterozygosity for both a rare BMPR 2 mutation and common TGF $\beta$ SNPs in the TGF $\beta /$ BMP signaling pathways interact to influence expression of the FPAH phenotype.

\section{MATERIALS AND METHODS}

\section{Patient recruitment and evaluation}

Study subjects were recruited over a 20-year period through our Pulmonary Hypertension Center, the Pulmonary Hypertension Association, and the National Institutes of Health Clinical Trials website (http://clinicaltrials.gov). The 81 family members with FPAH and a proven BMPR2 mutation were treated at centers throughout the United States and most are deceased. These 81 individuals were members of 55 nonrelated FPAH kindreds. Of these, 40 families were represented by one subject, whereas 11 families contributed two subjects. The remaining 19 affected subjects represented four different families, with three, four, five, and seven subjects, respectively. PAH was diagnosed by lung pathology showing plexogenic pulmonary arteriopathy in the absence of alternative causes such as congenital heart disease, or by clinical and cardiac catheterization criteria. The latter included a mean pulmonary arterial pressure of $>25 \mathrm{~mm} \mathrm{Hg}$ with a pulmonary capillary or left atrial pressure of $<15 \mathrm{~mm} \mathrm{Hg}$, and exclusion of other causes of pulmonary hypertension in accordance with accepted international standards of diagnostic criteria. ${ }^{33,34}$ Pulmonary arterial pressures were similar, regardless of the age at diagnostic cardiac catheterization. Diagnosis of FPAH required a well-documented family history of PAH and clinical confirmation of FPAH by the above criteria. Clinical information on current age, $\mathrm{AAD}$, gender, and $\mathrm{PAH}$ status was confirmed by review of medical records. AAD for patients with FPAH was determined by the date of diagnostic cardiac catheterization or clinical evaluation that established the diagnosis. A careful scrutiny of available clinical data including AAD resulted in the inclusion of 61 of the 81 affected subjects for the analysis of factors influencing AAD. For the 39 unaffected members of our FPAH families who also had a proven $B M P R 2$ mutation, their age on the date of our last contact with them at study enrollment and blood draw was recorded and their AAD was censored at the age of enrollment. Thus, all subjects in this study were proven to have BMPR2 mutations and were classified as affected based on the presence of the FPAH diagnosis, versus mutation carriers without clinical evidence of PAH. The study was approved by the Institutional Review Board at Vanderbilt University Medical Center, and written informed consent was obtained from all study subjects. 


\section{Genotyping genomic DNAs for TGF $\beta$ SNPs}

Genomic DNA was prepared from whole blood using Gentra Systems' Puregene ${ }^{\circledR}$ DNA Purification Kit (Minneapolis, $\mathrm{MN}$ ) according to the manufacturer's protocol. Samples were genotyped for TGF $\beta 1-509$ and codon 10 SNPs by polymerase chain reaction (PCR) amplification of $25 \mathrm{ng}$ of genomic DNA using Elongase Enzyme Mix (Invitrogen, Carlsbad, CA) and 10 $\mu \mathrm{M}$ of each of the oligonucleotide primers. The sequences for the TGF $\beta 1$ - 509 primers were $5^{\prime}$-CAGTTGGCGAGAACAGTTGG-3' for the forward primer and 5' -CAGATGCGCTGTGGCTTT-3' for the reverse primer. The sequences for the TGF $\beta 1$ codon 10 primers were $5^{\prime}$-GCCACAGATCCCCTATTCAA-3' for the forward primer, and 5'-TCGATAGTCTTGCAGGTGGA-3' for the reverse primer. PCR cycling conditions for TGF $\beta 1-509$ were $94^{\circ} \mathrm{C}, 30$ seconds; 35 cycles of $94^{\circ} \mathrm{C}$, 30 seconds; $58^{\circ} \mathrm{C}, 45$ seconds; $68^{\circ} \mathrm{C}, 45$ seconds; then $68^{\circ} \mathrm{C}, 3$ minutes. PCR cycling conditions for TGF $\beta 1$ codon 10 were $95^{\circ} \mathrm{C}, 1$ minute; 35 cycles of $95^{\circ} \mathrm{C}, 1$ minute; $61^{\circ} \mathrm{C}, 1$ minute; $68^{\circ} \mathrm{C}, 1$ minute; then $68^{\circ} \mathrm{C}, 10$ minutes. Before sequencing, amplified products were purified with ExoSAP-IT (USB Corporation, Cleveland, OH). Sequencing reactions were performed using a forward primer (5'-GCCCAGTTTCCCTATCTGT-3') for TGF $\beta 1-509$ and another forward primer (5'-CCGTGGGATACTGAGACACC3') for TGF $\beta 1$ codon 10 and a BigDye Terminator v3.1 Cycle Sequencing Kit according to the manufacturer's protocol (Applied BioSystems, Foster City, CA). Samples were then analyzed by capillary electrophoresis using a 3100 Genetic Analyzer (Applied Biosystems). Genotypes were determined by analysis with Mutation Surveyor Software (SoftGenetics, State College, PA).

\section{NMD classification}

$B M P R 2$ mutations that produce stable mutant $B M P R 2$ transcripts that do not activate NMD, are referred to as NMDwhereas those whose transcripts are degraded by NMD are classified as NMD+. NMD status was based on the stability of the mutant transcript in lymphoblastoid cell lines derived from individuals with each mutation following incubation with or without an NMD inhibitor (Puromycin). ${ }^{7,9}$ All NMD$B M P R 2$ transcripts showed roughly equal proportions of mutant and normal BMPR2 transcripts with and without lymphoblastoid cell line incubation with Puromycin.

\section{Preparation of lung sections and SMAD analysis}

Immunohistochemical analysis of human tissue sections for phosphorylated SMAD2 (pSMAD2) was performed using reagents and methods that have been previously described. ${ }^{35}$ Samples were derived from control individuals without disease (death caused by trauma) and diseased control patients with either pulmonary hypertension associated with congenital heart disease/Eisenmenger syndrome or FPAH due to mutations in the BMPR2 gene ( $n=5$ in each group). The images were analyzed independently by two pathologists who were blinded to clinical diagnosis.

\section{Study design}

We hypothesized that Synergistic Heterozygosity for functional TGF $\beta 1$ SNPs further increases the TGF $\beta$ /BMP signaling imbalance in BMPR2 mutation heterozygotes $(\mathrm{MH})$ to modulate the AAD and the penetrance of FPAH and is associated with increased SMAD2 expression in the lung. To test our hypotheses we genotyped the TGF $\beta 1$ SNPs of BMPR2 MH and compared both the AAD and penetrance of FPAH among the TGF $\beta 1$ SNPs genotypes. We also examined the expression of TGF $\beta /$ BMP dependent SMAD2 in lung sections from individuals with FPAH.

\section{Data analysis and statistics}

The test proposed by Weir ${ }^{36}$ was applied for Hardy Weinberg equilibrium (HWE). Kaplan-Meier disease free survival curve for AAD was constructed for TGF 31 SNP genotype groups. Log rank test was used to compare the curves between groups. For FPAH patients, their AAD was compared using Wilcoxon rank sum test because the AAD was not normally distributed. $P$ values $<0.05$ were considered statistically significant and all tests were two-tailed. Analysis of the binary variable penetrance was undertaken using the chi-square test for trend (Mantel-Haenszel test) across the three genotypes for each SNP. $P$ values $<0.025$, in concordance with techniques of the Bonferroni correction, were considered statistically significant and all tests were two-tailed. Statistical analyses were performed on a personal computer with the statistical package SPSS for Windows (Version 14.0, SPSS, Chicago) and the statistical software R (www.r-project.org).

\section{RESULTS}

\section{TGF $\beta 1$ SNP genotypes}

The TGF $\beta$-509 and codon 10 SNP genotypes for affected individuals are shown in Tables 1 and 2. The $P$ values of tests for HWE for the affected (FPAH patients) were 0.723 and $<0.001$ for TGF $\beta$-509 and codon 10 SNP genotypes, respectively.

\section{AAD of FPAH and TGF 1 SNP genotypes}

$B M P R 2 \mathrm{MH}$ having the least active (CC) as opposed to more active (CT/TT) -509 TGF $\beta 1$ SNP genotypes had mean ages at

Table 1

TGF 1 1-509 SNP genotypes and the observed and expected allele distributions among all affected subjects

\begin{tabular}{|c|c|c|c|}
\hline & TGF $\beta 1-509$ & $\begin{array}{l}\text { Individuals } \\
\text { observed }^{a}\end{array}$ & $\begin{array}{l}\text { Individuals } \\
\text { expected }\end{array}$ \\
\hline$\Xi$ & $\mathrm{CC}$ & 36 & 39.5 \\
\hline $\begin{array}{c}5 \\
\stackrel{5}{5} \\
0 \\
0 \\
0 \\
0\end{array}$ & CT & 41 & 34.1 \\
\hline$\stackrel{T}{T}$ & TT & 4 & 7.4 \\
\hline 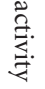 & Total & 81 & 81 \\
\hline
\end{tabular}

${ }^{a} \mathrm{C}=0.698$ and $\mathrm{T}=0.302$. 
Table 2

TGF $\beta 1$ codon 10 SNP genotypes and the observed and expected allele distributions among all affected subjects

\begin{tabular}{|c|c|c|c|}
\hline & TGF $\beta 1$ codon 10 & $\begin{array}{l}\text { Individuals } \\
\text { observed }^{a}\end{array}$ & $\begin{array}{l}\text { Individuals } \\
\text { expected }\end{array}$ \\
\hline$\Xi$ & TT & 19 & 26.7 \\
\hline 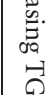 & TC & 55 & 39.6 \\
\hline 告 & $\mathrm{CC}$ & 7 & 14.7 \\
\hline 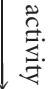 & Total & 81 & 81 \\
\hline
\end{tabular}

Table 3

Mean age at diagnosis of FPAH for different TGF $\beta 1$-509 SNP genotypes

\begin{tabular}{|c|c|c|c|}
\hline & TGFß1-509 & Age (yrs) & Individuals \\
\hline 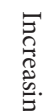 & $\mathrm{CC}$ & 39.5 & 29 \\
\hline 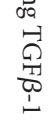 & $\mathrm{CT} / \mathrm{TT}$ & 31.6 & 32 \\
\hline 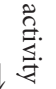 & Total & 35.4 & 61 \\
\hline
\end{tabular}

$P=0.03$ Wilcoxon.

Table 4

Mean age at diagnosis of FPAH for different TGF $\beta 1$ codon 10 SNP genotypes

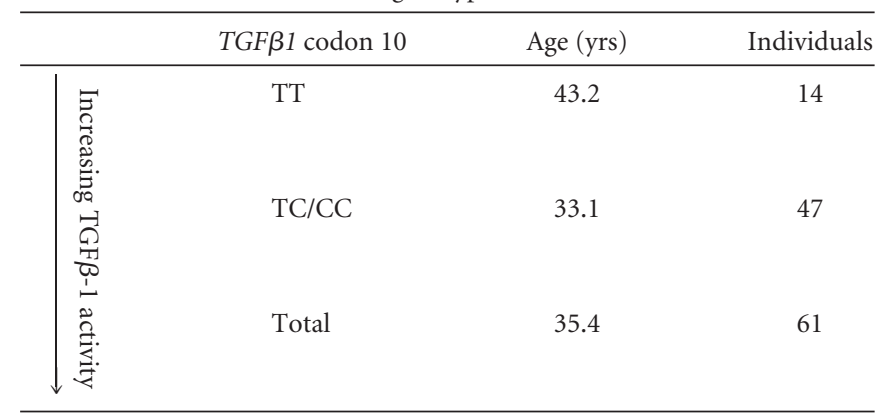

$P=0.02$ Wilcoxon.

diagnosis of FPAH of 39.5 and 31.6 years, respectively $(P=$ 0.03 Wilcoxon, Table 3). BMPR2 MH with the least active (TT) as opposed to more active (CT/CC) codon 10 TGF $\beta 1$ SNP genotypes had mean ages at diagnosis of 43.2 and 33.1 years, respectively $(P=0.02$ Wilcoxon, Table 4$)$.

\section{Kaplan-Meier analyses}

Kaplan-Meier analyses showed that those having the least active (CC) versus the more active (CT/TT) TGF 31 -509 SNP genotypes had later ages at diagnosis $(P=0.038 \log$ rank, Fig. $1)$. Also those having the least active (TT) versus the more active (CT/CC) TGF $\beta 1$ codon 10 SNP genotypes had later ages at diagnosis $(P=0.020 \log$ rank, Fig. 1$)$.

\section{Penetrance of FPAH in BMPR2 heterozygotes with TGF $\beta 1$ SNP genotypes}

The proportion of all NMD - BMPR2 $\mathrm{MH}$ who had FPAH was $0.33,0.72$, and 0.80 for those with CC (least active), CT (intermediate) and TT (most active) -509 genotypes $(P=$ 0.003 from $\chi^{2}$ trend test, Fig. 2). The proportion of all NMD$B M P R 2 \mathrm{MH}$ who had FPAH was $0.33,0.72$, and 0.75 for those with $0-1,2$, or $3-4$ active -509 or codon 10 SNP alleles $(P=$ 0.005 from $\chi^{2}$ trend test, Fig. 3).

\section{SMAD analysis of lung sections}

When compared with control individuals, the small to medium sized muscular arteries in the pulmonary circulation of individuals with FPAH showed increased TGF $\beta$ signaling in the medial layer of the vessel wall, as evidenced by increased nuclear accumulation of phosphorylated SMAD2 (pSMAD2), an intracellular mediator of the TGF $\beta$ transcriptional response (Fig. 4). This observation is unlikely to simply reflect a consequence of a chronic increase in pulmonary arterial pressure because increased TGF $\beta$ signaling was not observed in the pulmonary vasculature of individuals with Eisenmenger syndrome, a form of secondary pulmonary hypertension due to a chronic shunting of blood flow into the pulmonary circulation from the high-pressure systemic circulation (Fig. 4).

\section{DISCUSSION}

Although FPAH is autosomal dominant it has reduced penetrance and variable age of onset in BMPR2 MH.1,17,18 This suggests that the genetic background on which $B M P R 2$ mutations occur, along with the expression levels of the mutant and normal BMPR2 alleles, and possible environmental factors may affect penetrance and age of onset of FPAH. Identifying the genetic variations in susceptibility and modifier genes that enhance or inhibit phenotypic expression could provide insights that might allow directed intervention strategies to be developed. To better understand the role of modifier genes in FPAH we studied the relationship between variations in the number of active TGF $\beta$ SNPs and the AAD and penetrance of FPAH in BMPR2 MH.

The TGF $\beta 1$-509 and codon 10 SNP gene frequencies were $\mathrm{C}=0.69, \mathrm{~T}=0.31$ and $\mathrm{C}=0.43, \mathrm{~T}=0.57$, respectively (Tables 1 and 2). From these frequencies the expected numbers of individuals of various genotypes were calculated using the Hardy Weinberg formula. Tests for HWE showed that the codon 10 genotypes deviated from HWE. To exclude the possibility of genotyping errors, we regenotyped both SNPs from fresh aliquots of all genomic DNA samples and genotyping errors were ruled out. One possible explanation for the deviation from HWE may be our study ascertainment. In this aspect of our study, every subject has a BMPR2 mutation. Thus, our study sample comprises a stratum from the general population, rather than a representative sample. Secondly, this analysis fo- 

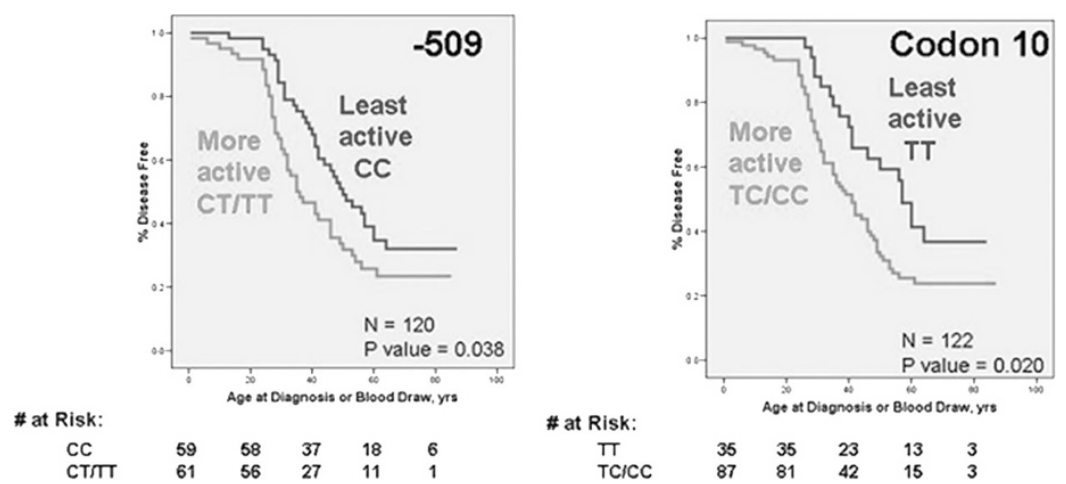

Fig. 1. Kaplan-Meier survival analysis of the age at diagnosis of FPAH or blood draw of unaffected BMPR2 mutation heterozygotes (MH) and the number of active -509 (left) or codon 10 (right) TGF $\beta 1$ SNP alleles.

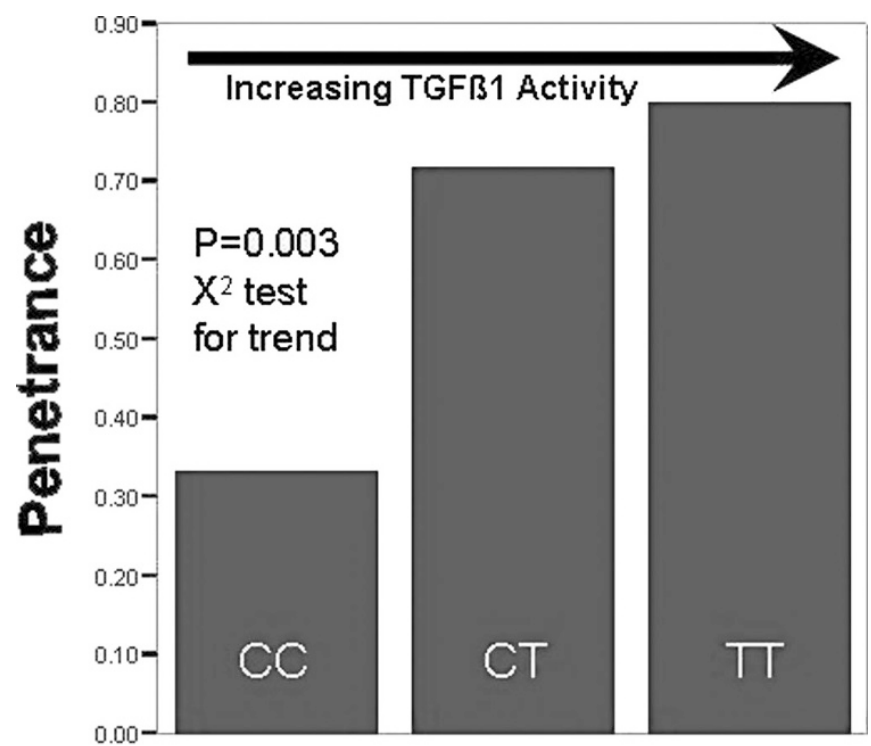

-509 SNP Genotypes

Fig. 2. Penetrance of FPAH in nonsense-mediated decay negative (NMD-) BMPR2 MH with -509 TGF 31 SNP genotypes. The proportion of all NMD- BMPR2 MH was $0.33,0.72$, and 0.80 for those with CC (least active), CT (intermediate), and TT (most active) -509 genotypes.

cuses on the affected, and HWE is generally expected to be distorted in the case sample in the region of association. ${ }^{37}$

We hypothesized that increased TGF $\beta$ activation from more active TGF $\beta$ alleles, coupled with reduced BMPR2 function from heterozygosity for a $B M P R 2$ mutation can further increase the imbalance in the TGF $\beta / B M P$ signaling ratio to contribute to an earlier AAD and increased penetrance of FPAH. We tested our hypotheses first by studying the association of common, functional TGF $\beta 1$ SNPs and AAD of those having FPAH (Tables 3 and 4 and Figs. 1 and 2). We also determined the penetrance of FPAH in all NMD- BMPR2 MH with different TGF $\beta$ SNP genotypes (Figs. 3 and 4). Both earlier AAD and increased penetrance was seen in those with more active $T G F \beta$ SNP genotypes. To evaluate the potential that familial clustering may contribute to these findings, we excluded fam-

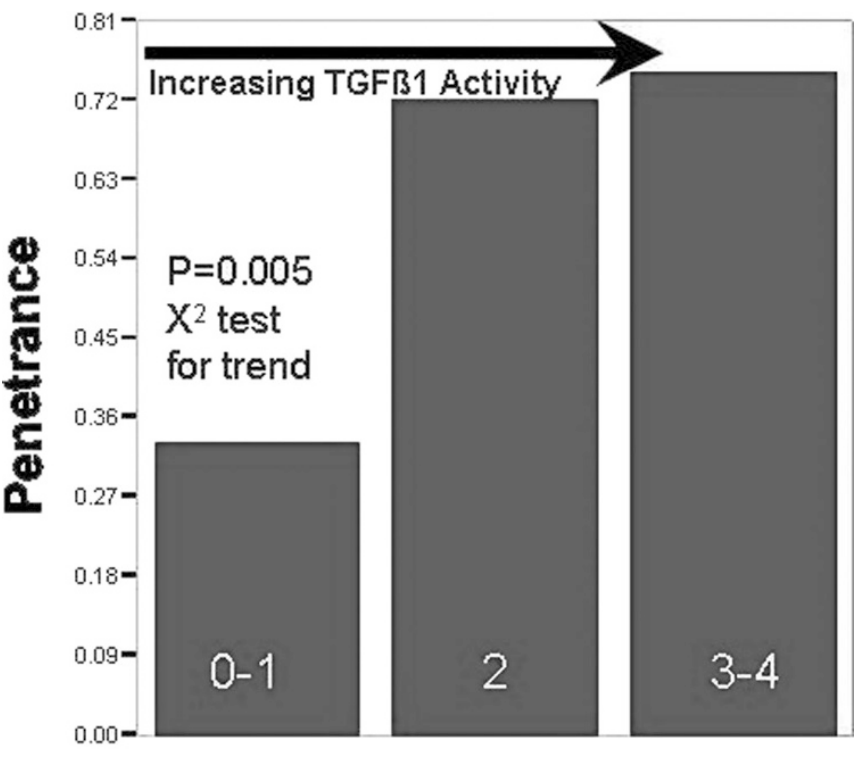

Number of Active Alleles

Fig. 3. Penetrance of FPAH in NMD - BMPR2 $\mathrm{MH}$ with the number of -509 and codon 10 TGF $\beta 1$ SNP alleles with increased activity. The proportion of all NMDBMPR2 MH who had FPAH was $0.33,0.72$, and 0.75 for those with $0-1,2$, or 3-4 active -509 or codon 10 SNP alleles, respectively.

ilies having more than two affected individuals, and reanalyzed the data. Despite a loss of power due to the exclusion of 19 affected subjects and 17 unaffected heterozygotes, a significantly younger $\mathrm{AAD}$ and increased penetrance was again seen in those with more active TGF $\beta$ SNP genotypes. In addition, many of the remaining subjects from the $11 \mathrm{FPAH}$ kindreds with two affected members were distantly related. Thus, even for the few remaining closely related members the probability for concordance for TGF $\beta$ SNP genotype is expected to be similar to that of the general population because of the high frequencies of the SNP alleles. Finally, when we selected only the youngest affected BMPR2 MH from each family for which mutation and SNP data were available we observed the same affects of the SNPs on AAD (data not shown). Thus, we feel that the contribution of familial clustering is negligible. 

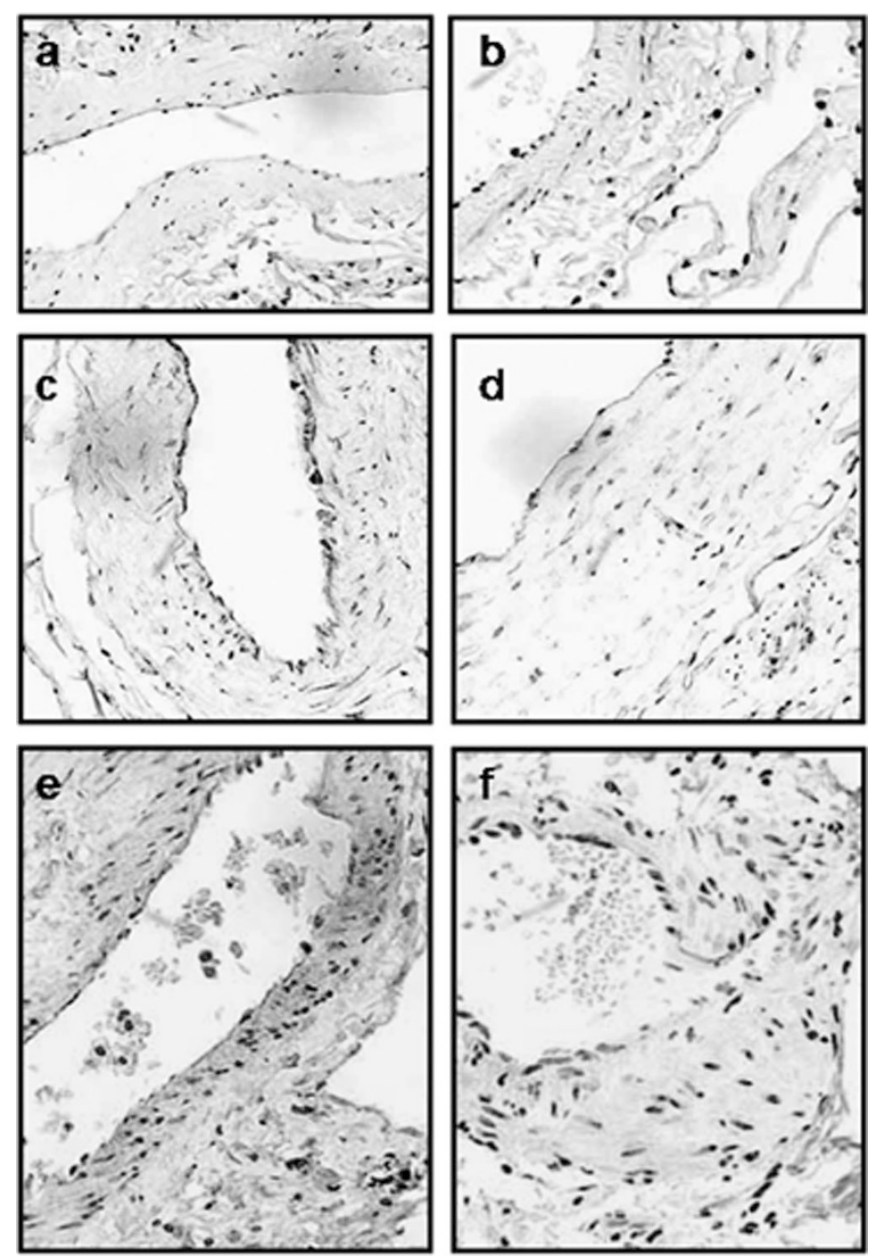

Fig. 4. TGF $\beta$ signaling, as marked by nuclear accumulation of phosphorylated SMAD2 (pSMAD2). In small to medium sized muscular arteries in the pulmonary circulation in normal lung $(\mathrm{a}, \mathrm{b})$, lung from individuals with secondary pulmonary hypertension (Eisenmenger syndrome; c, d), and lung from individuals with primary pulmonary hypertension caused by mutations in BMPR2 (e, f). Fields are representative of those observed in five individuals in each phenotypic category. Magnification $\times 20$ (a, c, e) and $\times 40($ b, d, f).

Our finding that TGF $\beta 1$ SNPs are associated with AAD and penetrance agrees with other evidence that increased TGF $\beta$ activity promotes pulmonary vascular disease in genetic association studies. ${ }^{24,29,30}$ Multiple, common human TGF $\beta$ ligand SNPs are known to affect TGF $\beta$ activation..$^{25,38}$ In twin studies the TGF $\beta 1$ concentration was shown to be predominantly under genetic control (heritability estimate 0.54 ).

Also in support of our hypothesis that imbalanced TGF $\beta$ /BMP signaling due to the presence of functional TGF $\beta$ SNP alleles correlates with the AAD and penetrance of FPAH (Tables 3 and 4 and Figs. 1-3), we found that SMAD2, which is induced by TGF $\beta$, shows increased relative expression in lung sections of individuals with FPAH (Fig. 4). Thus, our data in aggregate, suggest that common TGF $\beta$ SNPs and rare BMPR2 mutations combine to increase the imbalance between the downstream pathways of TGF $\beta$ and BMPR 2 signaling to accelerate the diagnosis of FPAH (Fig. 5).

Our data suggesting the potential role of TGF 1 SNPs as modifier genes for FPAH are analogous to findings in CF. ${ }^{24}$
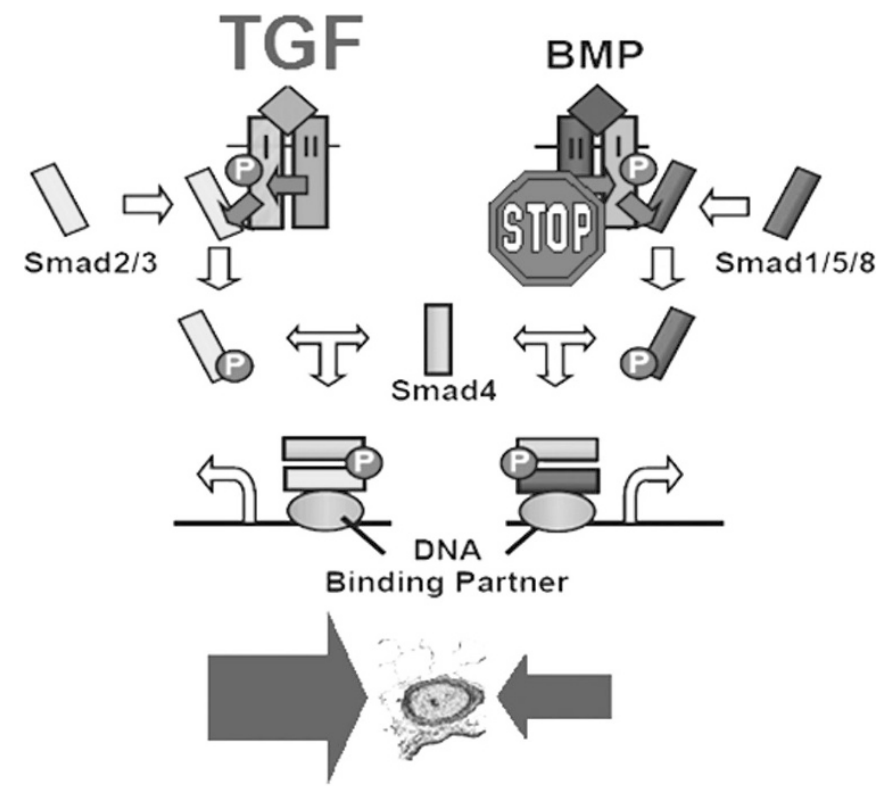

\section{Increased imbalance in regulation of cellular proliferation \& apoptosis}

Fig. 5. Model of imbalanced TGF $\beta / B M P$ pathway signaling and Synergistic Heterozygosity for rare BMPR2 mutations and common, functional TGF $\beta 1$ SNPs that can cause earlier age at diagnosis, increased penetrance, and increased SMAD2 accumulation in FPAH.

Importantly, our results suggest that possible clinical therapies could target the TGF $\beta /$ BMP signaling imbalance. Several potential approaches exist, which, except for Losartan in Marfan syndrome and Imatinib (Gleevec) in PAH have not been tested in humans. ${ }^{39-41}$ Losartan attenuates pulmonary arterial remodeling and increased BMPR2 expression in a swine model. ${ }^{42}$ Excess TGF $\beta 1$ activity is associated with Fibrillin mutations in Marfan syndrome. ${ }^{43}$ Losartan is an angiotensin receptor blocker that reduces cleavage of TGF $\beta 1$ from its latent complex and prevents aortic aneurysms in a murine model of Marfan syndrome; it is in clinical trials in human Marfan syndrome. ${ }^{44}$

The mechanisms underlying genetic anticipation in FPAH have yet to be elucidated. ${ }^{1,2}$ Our finding that the number of more active TGF $\beta$ SNPs correlates with AAD and penetrance suggests that polymorphic variation in TGF $\beta 1$ may contribute to genetic anticipation. Our data indicate that BMPR2 MH with no active TGF $\beta 1-509$ or codon 10 SNPs have a later AAD and constitute the minority (47 and $23 \%$, respectively) of affected individuals studied (Tables 3 and 4). Thus, BMPR2 MH with a later AAD are more likely to lack more active $T G F \beta$ SNPs. Because population data indicates that most in the normal population would have one or more active alleles, offspring who inherit the BMPR2 mutation from an affected parent who has no active TGF $\beta$ SNPs would likely have one or two active TGF $\beta$ SNPs they inherited from their "normal " parent. Thus the child, unlike their BMPR2 heterozygous parent, would have one or two active TGF $\beta$ SNPs that promote an earlier $\mathrm{AAD}$ and increased penetrance. Our conclusion regard- 
ing the potential effects of SNP genotypes on apparent anticipation is supported by our seeing the same effects of SNPs on $\mathrm{AAD}$ when we analyzed only the youngest affected $B M P R 2$ $\mathrm{MH}$ from each family having available mutation and SNP data. In summary, we think this could exemplify "synergistic anticipation" in which older onset BMPR2 heterozygotes with younger onset children lack, while their children usually possess, common $T G F \beta$ SNPs that are associated with earlier AAD of FPAH.

Finally, we think that the interactions between these TGF $\beta$ SNPs and BMPR2 mutations create cases of double and triple heterozygosity that are examples of "Synergistic Heterozygosity." 31,32 In the case of FPAH, heterozygosity for more active $\operatorname{TGF} \beta$ alleles is predicted to further increase the imbalance in the TGF $\beta /$ BMP signaling ratio that is already enhanced as a result of heterozygosity for a BMPR2 mutation. In FPAH this Synergistic Heterozygosity occurs in reciprocal, interactive pathways as shown in Figure 5. It is also possible that additional, but as yet unknown, polymorphisms in other genes in the TGF $\beta$ pathway may also contribute to this synergism.

\section{ACKNOWLEDGMENTS}

These studies were supported in part by National Institutes of Health Grants PO1 HL072058 and GCRC RR000095.

\section{References}

1. Newman JH, Wheeler L, Lane KB, Loyd E, et al. Mutation in the gene for bone morphogenetic protein receptor II as a cause of primary pulmonary hypertension in a large kindred. N Engl J Med 2001;345:319-324.

2. Loyd JE, Butler MG, Foroud TM, Conneally PM, et al. Genetic anticipation and abnormal gender ratio at birth in familial primary pulmonary hypertension. Am J Respir Crit Care Med 1995;152:93-97.

3. Lane KB, Machado RD, Pauciulo MW, Thomson JR, et al. Heterozygous germ-line mutations in BMPR2, encoding a TGF- $\beta$ receptor, cause familial primary pulmonary hypertension. The International PPH Consortium. Nat Genet 2000;26:81-84.

4. Deng Z, Morse JH, Slager SL, Cuervo N, et al. Familial primary pulmonary hypertension (gene PPH1) is caused by mutations in the bone morphogenetic protein receptor-II gene. Am J Hum Genet 2000;67:737-744.

5. Machado RD, Pauciulo MW, Thompson JR, Lane KB, et al. BMPR2 haploinsufficiency as the inherited molecular mechanism for primary pulmonary hypertension. Am J Hum Genet 2001;68:92-102.

6. Atkinson C, Stewart S, Upton PD, Machado R, et al. Primary pulmonary hypertension is associated with reduced pulmonary vascular expression of type II bone morphogenetic protein receptor. Circulation 2002;105:1672-1678.

7. Cogan JD, Vnencak-Jones CL, Phillips JA III, Lane KB, et al. Gross BMPR2 gene rearrangements constitute a new cause for primary pulmonary hypertension. Genet Med 2005;7:169-174.

8. Machado RD, Aldred MA, James V, Harrison RE, et al. Mutations of the TGF- $\beta$ type II receptor BMPR2 in pulmonary arterial hypertension. Hum Mutat 2006;27:121132.

9. Cogan JD, Pauciulo MW, Batchman AP, Prince MA, et al. High frequency of BMPR2 exonic deletions/duplications in familial arterial hypertension. Am J Resp Crit Care Med 2006;174:590-598.

10. Yang X, Long L, Southwood M, Rudarakanchana N, et al. Dysfunctional Smad signaling contributes to abnormal smooth muscle cell proliferation in familial pulmonary arterial hypertension. Circ Res 2005;96:1053-1063.

11. Mitas M. Trinucleotide repeats associated with human disease. Nucleic Acids Res 1997;25:2245-2254.

12. Le Hir H, Izaurralde E, Maquat LE, Moore MJ. The spliceosome deposits multiple proteins 20-24 nucleotides upstream of mRNA exon-exon junctions. EMBO J 2000;19:6860-6869.

13. Le Hir H, Izaurralde E, Maquat LE. Pre-mRNA splicing alters mRNP composition: evidence for stable association of proteins at exon-exon junctions. Genes Dev 2000; 14:1098-1108.

14. Yamashita H, Ten Dijke P, Heldin CH, Miyazono K. Bone morphogenetic protein receptors. Bone 1996;19:569-574.

15. Nohe A, Hassel S, Ehrlich M, Neubauer F, et al. The mode of bone morphogenetic protein (BMP) receptor oligomerization determines different BMP-2 signaling pathways. J Biol Chem 2002;277:5330-5338.

16. Sakou T, Onishi T, Yamamoto T, Nagamine T, et al. Localization of Smads, the TGF-beta family intracellular signaling components during endochondral ossification. J Bone Miner Res 1999;14:1145-1152.

17. Newman JH, Fanburg BL, Archer SL, Badesch DB, et al. Pulmonary arterial hypertension: future directions: report of an NHLBI/ORD Workshop. Circulation 2004, 109:2947-2952.

18. Newman JH, Trembath RC, Morse JA, Grunig E, et al. Genetic basis of pulmonary arterial hypertension: current understanding and future directions. J Am Coll Cardiol 2004;43:S33-S39.

19. Morrell N. Pulmonary hypertension due to BMPR2 mutations. Proc Am Thoracic Soc 2006;3:680-686.

20. Eddahibi S, Hanoun N, Lanfumey L, Lesch KP, et al. Attenuated hypoxic pulmonary hypertension in mice lacking the 5-hydroxytryptamine transporter gene. J Clin Invest 2000;105:1555-1562.

21. Eddahibi S, Humbert M, Fadel E, Raffestin B, et al. Serotonin transporter overexpression is responsible for pulmonary artery smooth muscle hyperplasia in primary pulmonary hypertension. J Clin Invest 2001;108:1141-1150.

22. Willers ED, Newman JH, Loyd JE, Robbins IM, et al. Serotonin transporter polymorphisms in familial and idiopathic pulmonary arterial hypertension. Am J Respir Crit Care Med 2006;173:798-802.

23. Haston CK, Hudson TJ Jr. Finding genetic modifiers of cystic fibrosis. N Engl J Med 2005;353:1509-1511.

24. Drumm ML, Konstan MD, Schluchter MD, Handler A, et al. Genetic modifiers of lung disease in cystic fibrosis. N Engl J Med 2005;353:1443-1453.

25. Grainger DJ, Heathcote K, Chiano M. Genetic control of the circulating concentration of transforming growth factor type beta 1. Hum Mol Genet 1999;8:93-97.

26. Silverman ES, Palmer LJ, Subramaniam V, Hallock A, et al. Transforming growth factor-betal promoter polymorphism C-509T is associated with asthma. Am J Respir Crit Care Med 2004;169:214-219.

27. Shah R, Hurley CK, Posch PE. A molecular mechanism for the differential regulation of TGF-beta-1 expression due to the common SNP-509C-T (c.-1347C-T). Hum Genet 2006;120:461-469.

28. Suthanthiran M, Li B, Song JO, Ding R, et al. Transforming growth factor-beta-1 hyperexpression in African-American hypertensives: a novel mediator of hypertension and/or target organ damage. Proc Nat Acad Sci 2000;97:3479-3484.

29. Grutters JC, du Bois RM. Genetics of fibrosing lung diseases. Euro Respir J 2005;25: 915-927.

30. Celedon JC, Lange C, Raby BA, Litonjua AA, et al. The transforming growth factorbetal (TGFB1) gene is associated with chronic obstructive pulmonary disease (COPD). Hum Mol Genet 2004;13:1649-1656.

31. Vockley J, Rinaldo P, Bennett MJ, Matern D, et al. Synergistic heterozygosity: disease resulting from multiple partial defects in one or more metabolic pathways. $\mathrm{Mo}$ Genet Metab 2000;71:10-18.

32. Schuler AM, Gower BA, Matern D, Rinaldo P, et al. Synergistic heterozygosity in mice with inherited enzyme deficiencies of mitochondrial fatty acid $\beta$ oxidation. Mol Genet Metab 2005;85:7-11.

33. Loyd JE, Primm RK, Newman JH. Familial primary pulmonary hypertension: clinical patterns. Am Rev Respir Dis 1984;129:194-197.

34. Simonneau G, Galie N, Rubin LJ, Langleben D, et al. Clinical classification of pulmonary hypertension. J Am Coll Cardiol 2004;43(12 suppl S):5S-12S.

35. Habashi JP, Judge DP, Holm TM, Cohn RD, et al. Losartan an AT1 antagonist, prevent aortic aneurysm in a mouse model of Marfan syndrome. Science 2006;12:117-121.

36. Weir BS. Genetic data analysis 2: methods for discrete population genetic data. Sunderland, MA: Sinauer Associates, Inc., 1996.

37. Nielsen D, Ehm MG, Weir BS. Detecting marker-disease association by testing for Hardy-Weinberg disequilibrium at a marker locus. Am J Hum Genet 1999;63:1531-1540.

38. Akhurst RJ. TGF beta signaling in health and disease. Nat Genet 2004;36:1024-1031.

39. Loeys BL, Chen J, Neptune ER, Judge DP, et al. A syndrome of altered cardiovascular, craniofacial, neurocognitive and skeletal development caused by mutations in TGFBR1 or TGFBR2. Nat Genet 2005;37:275-281.

40. Loeys BL, Schwarze U, Holm T, Callewaert BL, et al. Aneurysm syndromes caused by mutations in the TGF-beta receptor. N Engl J Med 2006;355:788-798.

41. Ghofrani HA, Weeger W, Grimminger F. Imatinib for the treatment of pulmonary arterial hypertension. N Engl J Med 2005;353:1412-1413.

42. Rondelet B, Kerbaul F, Van Beneden R, Hubloue I, et al. Prevention of pulmonary vascular remodeling and of decreased BMPR-2 expression by Losartan therapy in shunt-induced pulmonary hypertension. Am J Physiol Heart Circ Physiol 2005;289:H2319-H2324.

43. Robinson PN, Arteaga-Solis E, Baldock C, Collod-Beroud G, et al. The molecular genetics of Marfan syndrome and related disorders. J Med Genet 2006;10:769-787.

44. Lacro RV, Dietz HC, Wruck LM, Bradley TJ, et al. Rationale and design of a randomized clinical trial of $\beta$-blocker therapy (atenolol) versus angiotensin II receptor blocker therapy (losartan) in individuals with Marfan syndrome. Am Heart J 2007;154:624-631. 